\title{
Research on incentive mechanism of University Counselors Based on big data in the Internet Era
}

\author{
Wang Xiaoli, Gao Zhen, Wang Zuyi
}

Sanya Aviation \& Tourism College

Keywords: big data; college counselors; incentive mechanism

\begin{abstract}
Absrtact: With the rapid development of big data technology on the Internet, it is the focus of attention of colleges and universities to build a perfect incentive mechanism system for College Counselors Based on big data. Taking the course of MySQL Database Programming as an example, this paper puts forward the implementation strategy of incentive mechanism based on big data technology, and analyzes and summarizes the incentive mechanism system based on College counselors.
\end{abstract}

With the rapid development of big data technology on the Internet, the technology and products represented by big data are rapidly falling to the ground. Big Internet industry giants have taken the lead in establishing a perfect big data service system. Building a perfect incentive mechanism system for College Counselors Based on cloud technology is the focus of attention of colleges and universities. Large Internet enterprises have also developed cloud products and cloud services based on large data. As the products and services of big data technology become more and more mature, it is bound to change the mode of curriculum incentive mechanism in the field of education. It is foreseeable that the incentive mechanism based on big data is the future of Internet + education.

College counselors'incentive mechanism plays an important role in the reform of incentive mechanism and the cultivation of talents. Computer course incentive mechanism plays an incomparable role in the cultivation of College Students' basic skills. Computer data processing and application ability has become one of the basic qualities of College students, but also related to the students'job selection and job adaptability after employment [2]. Premier Li Keqiang has repeatedly proposed the idea of "Internet + education" to reform the field of education. However, some colleges and universities have not kept pace with the pace of modernization, and timely updated the traditional incentive mechanism concept, making the incentive mechanism and incentive mechanism process too conservative [3]. The application of big data technology changes people's way of thinking and learning, which is a serious challenge to education, but also for the reform and development of education provides a golden opportunity.

\section{The whole process of incentive mechanism to move to the big data side.}

Life cycle refers to the whole process from beginning to end. The life cycle of university curriculum is the whole process of management decision-making from the preparation before the beginning of the curriculum to the result statistics and big data analysis after the completion of the curriculum [4]. The whole process is more convenient and flexible under the big data technology. The life cycle of the curriculum is moving to the cloud. Teachers adopt the incentive mechanism model of college counselors to reduce the pressure of the incentive mechanism, which can improve the quality and efficiency of the incentive mechanism. Students adopt cloud learning mode, breaking the traditional time and space constraints, at any time and anywhere in a free learning platform for learning. Teachers deploy exams and exercises through the cloud evaluation platform. The results of exams and exercises can be uploaded to the cloud server automatically, and data statistics and analysis can be carried out at any time to make decisions [5].

Large data technology makes computing and storage move to the cloud, the user terminal is the display + thin terminal, all computing and storage in the cloud to complete, thin terminal only to complete the display function. The incentive mechanism cloud platform architecture for the whole 
process of incentive mechanism relocation to the cloud makes the cost of "display + thin terminal" greatly reduced, just like the desks and chairs in the classroom, become a necessity. Relocation of computing and storage to the cloud has become a prevalent trend, which can save school education expenditure and reduce the pressure of equipment maintenance [5].

Therefore, through the rational application of the functional advantages of large data technology, the entire incentive mechanism process can be realized in the large data platform, can share incentive mechanism resources, to achieve online college counselors incentive mechanism, cloud learning, cloud testing, thus effectively cultivating students'hands-on ability.

\section{Practice strategy of incentive mechanism based on big data}

Database technology is the core technology and important foundation of computer application system and information system. With the social needs and the development of computer information technology, the subjects of the National Computer Rank Examination have also made timely adjustments. The database subject "Level 2 VFP Database Programming" which has been tested for nearly 20 years has been suspended since September 2017. At present, there are two choices for computer secondary database related subjects: Access database, MySQL database [6]. Since MySQL is one of the most popular relational database management systems, many universities have also suspended VFP-related courses and switched to MySQL Database Programming. The following large data technology in the university database curriculum incentive mechanism for the application of practice, in order to provide reference for the current university curriculum incentive mechanism.

\subsection{Course characteristics}

According to the requirements of the National Computer Rank Examination Level II MySQL Database Programming Examination, the main contents of this course are: the basic concepts and methods of database, MySQL installation and configuration, MySQL platform using SQL language to achieve database interaction, MySQL database programming, using PHP application development language The development of simple application system, the management and maintenance technology of MySQL database [7].

The main task of this course is to cultivate students'basic skills in database use, and to cultivate students' ability to use PHP + MySql to develop database application system. The content theory of motivation mechanism is abstract and practical. The traditional incentive mechanism has been unable to meet the needs of society for the cultivation of practical talents.

\subsection{Incentive mechanism for College Counselors}

The main responsibility of colleges and universities is to teach and educate people. The most important way to teach and educate people is the incentive mechanism. To improve the quality and efficiency of teachers'incentive mechanism is one of the core tasks of many schools. How to combine the large data platform with the actual situation of the school to develop a set of effective incentive mechanism for college counselors is the focus of the relationship between many colleges and universities. Based on this understanding, the author's teaching and research department spent a lot of time on the application of the college counselor incentive mechanism model in the course of MySQL database programming, and accumulated a set of efficient implementation programs.

\subsubsection{Based on cloud host incentive mechanism}

Cloud host is the Internet infrastructure service that big data provides users with public utility. Using virtual software VZ or VM in the cloud to virtualize numerous similar parts of the independent host, each part can be a separate operating system, the management method is the same as the host. According to the need of College counselors'incentive mechanism, students' school number is the system account of College counselors'incentive mechanism, enjoying cloud services, such as cloud hosts, cloud learning, cloud evaluation. The process of incentive mechanism in this course can be carried out in the most practical way, like providing a single host for each student to 
play. In the cloud host system environment, students can learn to build the environment, such as installing and configuring Apache, MySQL, PHP and other services. Previous incentive mechanism room with restore card, MySQL configuration installed by students, optimization results can not be saved, hampering the enthusiasm of students to learn. The tasks completed by students in each class can be well recorded and saved by using the cloud host computer. With the perfect cloud evaluation system, each task score can be automatically given for teachers to refer to students'accomplishment in real time and adjust the incentive mechanism strategy.

\subsubsection{Online classroom driven task driven incentive mechanism}

According to the incentive mechanism content and task objectives of this course, the project of developing a complete database application system is divided into several tasks, such as MySQL environment configuration, database construction, data processing and view, database security and performance optimization, PHP access to MySQL database, etc. According to the time arrangement, each task is completed by one or more classes. Every time before class, teachers will assign the next class tasks, based on the "flipped classroom-based incentive mechanism" mode, students complete the task-related knowledge learning after class, and the classroom has become a place for teachers and students to answer questions and solve puzzles, thus achieving better educational results. In class, because of the incentive mechanism based on the large data machine platform, teachers'courseware, course content and other incentive mechanism resources are stored in the cloud, there is no need to worry about the incentive mechanism problems caused by the damage and loss of the $U$ disk. Teachers let students log on to the college counselor incentive system attendance, using broadcast incentive mechanism to explain the task objectives and related knowledge. For tasks that do not know how to accomplish, teachers guide students to complete the task by using electronic classroom demonstration method, but also students can follow the teacher operation, help students to complete the task on time. Students need to complete the task, and each task score will be averaged as a normal result, so that each class students have a clear goal of the task, can mobilize the enthusiasm of students to complete the task. In this process, the most important thing is to cultivate students' learning ability and problem-solving ability.

\subsubsection{Computer literacy motivation mechanism based on cloud network}

The advantage of teaching in the cloud environment is that you can use search engines to solve difficult problems at any time, and the knowledge you need to master can also be obtained through search engines. This can broaden students'learning horizons and help to cultivate outstanding people with strong ability. For example, learning PHP, MySQL can check the PHP manual, MySQL manual and other network resources, to strengthen the practical application of students'knowledge of this course.

Based on this course is a highly practical course, can also provide Aliyun and other cloud virtual hosts or cloud servers and other network resources, so that students try to complete the task of project release, update and maintenance operations.

Another goal of this course is to develop computer literacy. (1) learn to use search engines to solve problems. We are not the first to eat crabs. If you encounter a problem or a program error, you know you are trying to find the answer in the book first; if there is no answer in the book, you can find the problem through the Baidu search engine (intended to train students'self-learning ability, their ability to solve problems); if the problem is still unsolved, you should first consider negotiating with other students to solve it. It is intended to exercise synergy, until the teacher is consulted to solve the problem. (2) Learning how to find knowledge is more important than knowing the details of knowledge. (3) learning to learn by oneself is more important than learning knowledge. It is more important to learn knowledge than to learn knowledge. "Learning knowledge" is at a low level, that is, learning a specific knowledge. The level of "learning knowledge" is high, and it is intended to emphasize self-learning ability. The advantage of this course is that it allows students to swim freely in the sea of knowledge such as search engine and stimulates students'learning potential. 


\subsection{Big data learning}

In a large data environment, around learning services, key models such as cloud knowledge, cloud tasks, cloud resources, cloud websites are built, and an open learning system is developed using software architecture and Web interactive technology. At any time, students can login to Web platform or mobile APP platform to learn.

Using cloud platform to effectively integrate incentive mechanism resources can make full use of incentive mechanism resources to carry out a unified incentive mechanism. Storing and releasing incentive mechanism resources in the cloud can enable learners to fully access learning resources, carry out curriculum learning activities anytime and anywhere, obtain learning resources according to their own needs, and interact with teachers in a timely manner, so as to achieve the purpose of virtualization incentive mechanism.

\subsection{Big data evaluation}

The traditional examination system uses C/S structure or B/S structure, the server configuration is more complex, the upgrade and maintenance workload is larger, the hardware, system, network requirements are higher. Test system based on large data, all resources are stored in the cloud, data processing is running in the cloud, do not need to purchase expensive test server software and hardware systems, greatly saving costs. Traditional test system hardware and software products are moving to the cloud. Teachers only need to deploy various kinds of tests and exercises through the cloud. Students can install cloud clients on PC, mobile phone and tablet to test and practice everywhere. Examination and practice results are automatically uploaded to the cloud server, and managers can carry out data statistics and analysis at any time.

\section{Analysis of the application of incentive mechanism based on big data}

After years of practice, the Computer Engineering Department of CAAC has adopted the whole incentive mechanism scheme of college counselors since 2016, which runs through the whole incentive mechanism process. On the basis of the incentive mechanism of College counselors, cloud learning and cloud testing, the traditional incentive mechanism has been thoroughly reformed, and the whole course network incentive mechanism and network examination brought by the teaching and research department have been realized. Since the incentive mechanism cloud platform was adopted, after two years of practice, the effect of incentive mechanism has been significantly improved. The student's average score has been greatly reduced. Large data assistant incentive mechanism is a very important incentive mechanism model, therefore, counselor incentive mechanism system construction must strengthen the exploration and application of large data

\section{References}

[1] Zhou Yong. Application of Big Data Auxiliary Incentive Mechanism in Higher Vocational Course Incentive Mechanism [J].China New Communication. 2018 (6): 191.

[2] Zhu Xu. Practical Exploration of University Network Incentive Mechanism Based on Big Data [J]. Wireless Interconnection Technology. Wireless Interconnection Technology. 2018 (4): 31-32

[3] Chen Weijie. Reflections on the Reform of Practical Incentive Mechanism in Colleges and Universities from the Perspective of Innovative and Entrepreneurial Ability [J].

[4] Han Dan. The application of electronic classroom in the incentive mechanism and management of computer room [J].Sci-tech horizon. 2016, (5): 160.

[5] Xu Guoqiang, Ren Hongwei. Research on the Practical Incentive Mechanism Model of Emphasizing Quality Education and Application Ability Training [J]. Forum on Educational Incentive Mechanism. 2015, (21): 278-280.

[6] Application of Cheng Yuan, Fan Guanghui and WebQuest in the Incentive Mechanism of 
Database Programming [J]. Computer Knowledge and Technology. 2013, (29): 6479-6480.

[7] Huang Lusheng, Xie Qi, Deng Yi, et al. [J]. Journal of Hunan City University. 2013, (5): 79-81.

[8] Chuxiao, Han Yan, Liang Zhixing. Research on the Key Links of the Quality Evaluation System of Practical Incentive Mechanism in Colleges and Universities [J].China Adult Education. 2013, (4): 36-38. 